\title{
POLA SEBARAN EROSI DAN SEDIMENTASI SUNGAI SEKANAK
}

\author{
Achmad Syarifudin', Dinar Febriansyah ${ }^{2)}$, Henggar Ria Destania ${ }^{3)}$ \\ Program Studi Teknik Sipil, Universitas Bina Darma/HATHI Cabang Sumsel ${ }^{1)}$ \\ Mahasiswa Prodi Teknik Sipil Universitas Bina Darma Palembang ${ }^{2)}$ \\ Dosen Program Studi Teknik Sipil Universitas Indo Global Mandiri Palembang ${ }^{3)}$ \\ syarifachmad6080@yahoo.co.id ${ }^{1)}$
}

\begin{abstract}
ABSTRAK
Sebagai salah satu sumber daya, potensi yang terkandung dalam air dapat memberikan manfaaat ataupun kerugian bagi kehidupan dan penghidupan manusia serta lingkungannya. Perubahan fungsi lingkungan yang disebabkan oleh laju pertumbuhan jumlah penduduk,serta meningkatnya aktivitas masyarakat dalam memenuhi kebutuhan hidup,telah berdampak negatif terhadap kelestarian sumber daya air,serta meningkatnya perubahan sungai akibat daya rusak air yang disebabkan antara lain berupa banjir,erosi dan sedimentasi. Penelitian bertujuan untuk menghitung besarnya total bedload serta pola erosi dan sedimentasi yang terjadi di muara sungai Sekanakdengan pendekatan model fisik pada saluran di laboratorium Fakultas Teknik Universitas Bina Darma Palembang dengan dimensi sungai dibuat skala laboratorium. Hasil penelitian dapat disimpulkan bahwa besarnya total bedload yang terjadi pada muara sungai Sekanak adalah sebesar $105,926 \mathrm{~m} 3 /$ hari atau $6720 \mathrm{~m} 3 /$ tahun dengan hasil ini maka direkomendasikan juga periode waktu pengerukan adalah minimal 29 bulan atau 2 tahun sekali sedangkan pola pergerakkan sedimen yang terjadi berbentuk chute and pool.
\end{abstract}

Kata kunci : flood plains, total bed load, pola sedimentasi, sungai sekanak

\section{PENDAHULUAN}

Sungai Musi merupakan sungai utama dengan panjang sungai lebih dari $750 \mathrm{~km}$ dan lebar rerata $540 \mathrm{~m}$ masih terpengaruh oleh pasang surut air laut dari tiga belas sistem DAS yang ada dan salah satu sungai yang dimaksud adalah sungai Sekanak dimana perubahan pada sungai sekanak ini terjadi akibat dari faktor alam dan faktor manusia seperti adanya bangungan air pada badan sungai seperti pilar, abutmen dan sebagainya. Sifat dinamis pada sungai, suatu waktu akan dapat memberikan pengaruh kerusakan pada bangunan yang ada disekitarnya.

Wilayah fisiografi Palembang terletak pada dataran rendah berupa flood plains dan termasuk pada wilayah endapan yang potensial sebagai tempat genangan air.
Potensi-potensi genangan ini merupakan faktor yang perlu di pertimbangkan bagi sebagian besar wilayah kota Palembang.

Salah satu permasalahan yang terjadi pada sungai Sekanak adalah sedimentasi. Proses sedimentasi berjalan sangat komplek, diawali dengan turunnya air hujan yang menghasilkan energi kinetik sebagai awal proses erosi pada permukaan tanah. Ketika tanah menjadi partikel halus, sebagian akan tertinggal dan sebagian lainnya terbawa aliran air kemudian masuk pada badan air atau sungai sehingga menjadi angkutan sedimen.

Perubahan pada sungai umumnya terjadi akibat dari faktor alam atau faktor manusia seperti adanya bangunan bangunan air pada badan sungai seperti pilar, abutmen, bending dan sebagainya. Sifat dinamis pada sungai, suatu waktu akan dapat 
memberikan pengaruh kerusakan pada bangunan yang ada disekitarnya.Salah satu permasalahan yang terjadi pada sungai adalah sedimentasi.Proses sedimentasi berjalan sangat komplek, diawali dengan turunnya air hujan yang menghasilkan energi kinetik sebagai awal proses erosi pada permukaan tanah. Ketika tanah menjadi partikel halus, sebagian akan tertinggal dan sebagian lainnya terbawa aliran air kemudian masuk pada badan air atau sungai sehingga menjadi angkutan sedimen.

Berdasarkan penelitian, semakin besar debit yang dialirkan maka angkutan sedimen (Bed Load) akan semakin banyak (Cahyono iksan 2007).Angkutan sedimen tersebut pada waktu tertentu akan diendapkan pada suatu tempat. Sedimentasi dapat terjadi pada badan sungai ataupun muara sungai .Sehubungan dengan hal tersebut diatas, perlu diadakan studi eksperimen mengenai pergerakan sedimen pada saluran terbuka.

\section{METODOLOGI PENELITIAN}

Penelitian ini dilakukan dengan pendekatan model fisik flume sederhana (gambar 1) di laboratorium Fakultas Teknik Universitas Bina Darma Palembang

\subsection{Bahan dan Alat Penelitian}

Dalam penelitian ini digunakan beberapa alat dan bahan yang di gunakan untuk pembuatan saluran dan pengamatan selama simulasi berlangsung.

\subsection{Air}

Air yang digunakan dalam penelitian ini adalah air yang diperoleh dari Laboratorium Hidrulika dan Sumber Daya Air Jurusan Teknik Sipil, Fakultas Teknik, Universitas Bina Darma.

\subsubsection{Material sedimen}

Material sedimen yang digunakan adalah sedimen pasir tanjung raja kemudian pasir dicuci dan dijemur untuk membersihkan dari lumpur dan kotorankotoran dan pasir yang digunakan sebagai kemudian diayak dengan nomor ayakan 20.

\subsection{Alat-Alat Penelitian}

Open Flume, merupakan alat utama dalam percobaan loncatan hidrolis, gerusan dan sedimen.Flume ini, sebagian besar komponennya terbuat dari kaca dan memiliki bagian-bagian penting, yaitu:

- Saluran air, Tempat utama dalam percobaan ini, untuk mengalirkan air. Berupa flume dengan ukuran 400x20x15 $\mathrm{cm}$. Saluran air berdinding transparan untuk mempermudah pengamatan.

- Bak penampung, yang berfungsi menampung air yang akan dialirkan ke flume maupun yang keluar dari saluran,

- Pompa air, berfungsi untuk memompa air agar bisa didistribusikan sepanjang talang air. Pompa ini dilengkapi dengan tombol on/off otomatis untuk supply listrik 220/240 V, $50 \mathrm{~Hz}$.

- Kran debit, merupakan kran yang berfungsi mengatur besar-kecilnya debit yang keluar dari pompa. Memiliki skala bukaan debit 6-9 range.

- Roda pengatur kemiringan, terletak di hulu dan hilir saluran yang bisa diputar secara manual untuk mengatur kemiringan dasar saluran (bed slope) yang diinginkan. Roda pengatur bed slope nimemiliki skala untuk maximum positive bed slope+ 3,0\% dan maximum negative bed slope- $1,0 \%$.

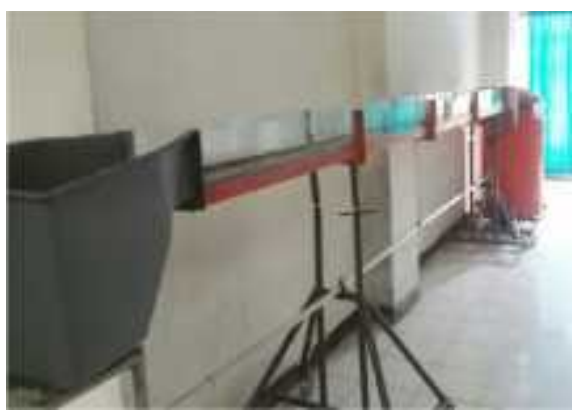

Gambar1.Model saluranterbuka(open channel flume) 


\section{HASIL DAN PEMBAHASAN \\ 3.1. Analisis Kadar Lumpur}

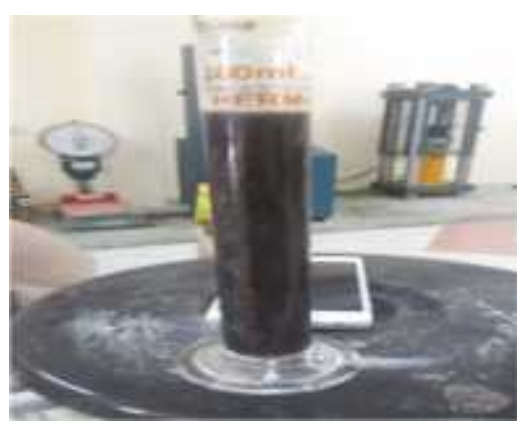

\section{Gambar 2. Kadar lumpur}

Analisis kandungan lumpur dilakukan untuk mencari persentase kandungan lumpur yang terdapat di badan sungai, dan hasil analisis kadar lumpur ditemukan menjadi $9,70 \%$, yang berarti bahwa kandungan lumpur di sungai sekanak kebanyakan mengandung lumpur.

\subsection{Pola dan Sebaran Sediment Transport}

Dari hasil perhitungan transport sedimen dasar yang dilakukan dengan menggunakan rumus MPM, Einstein dan Lane, serta Frijlink memperoleh hasil seperti tabel di bawah ini

\section{Tabel 1. Hasil analisa angkutan Sediment}

\begin{tabular}{lccc}
\hline Lokasi & $\begin{array}{c}\text { MPM } \\
\mathbf{T b} \\
\left(\mathbf{m}^{\mathbf{3}} / \mathbf{h a r i}\right)\end{array}$ & $\begin{array}{c}\text { Einstein } \\
\text { dan Lane } \\
\mathbf{T b} \\
\left(\mathbf{m}^{\mathbf{3}} / \mathbf{h a r i}\right)\end{array}$ & $\begin{array}{c}\text { Frijlink } \\
\mathbf{T b} \\
\left(\mathbf{m}^{\mathbf{3}} / \mathbf{h a r i}\right)\end{array}$ \\
\hline Hilir & 105.926 & 17.85 & 1.2 \\
$\begin{array}{l}\text { Depan } \\
\begin{array}{l}\text { Pilar } \\
\text { jembatan }\end{array}\end{array}$ & & & \\
\hline
\end{tabular}

\subsection{Pola Erosi dan Sedimentasi}

Hasil pengamatan pola sedimen maka di dapat pola sedimen dengan pembagian tiga periode waktu yaitu 30 menit,60 menit dan 90 menit sehingga terbentuk pola sedimentasi seperti pada gambar di bawah ini.

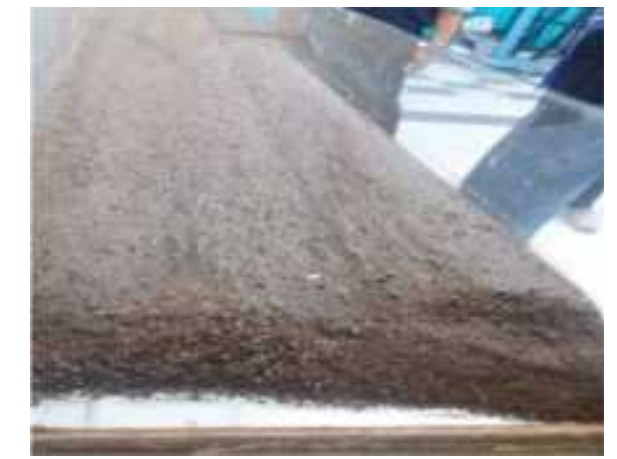

\section{Gambar 3. Pola Erois dan Sedimentasi pada waktu 30 Menit}

Pada Gambar 3 adalah pola yang terjadi selama interval waktu simulasi selama 30 menit dan hasilnya dapat dikatakan telah terjadi perubahan bentuk transpor sedimen di mulut sungai sekanak dengan bentuk gelombang mulai dari sisi sisi sungai

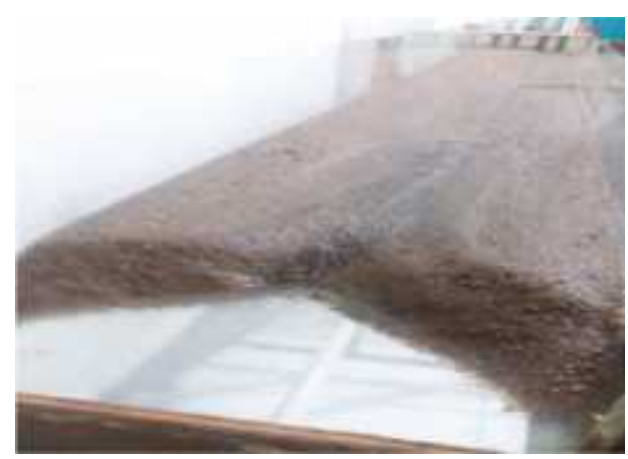

\section{Gambar 4. Pola Erosi dan Sedimentasi pada waktu 60 Menit}

Pada Gambar 4 adalah pola yang terjadi selama interval waktu simulasi selama 60 menit dan hasilnya dapat dikatakan telah terjadi perubahan bentuk transpor sedimen di mulut sungai sekanak Pola bergelombang yang lebih besar ditemukan pada arah badan sungai dan ini dimungkinkan karena laju aliran yang lebih besar bergerak di tengah badan sungai 


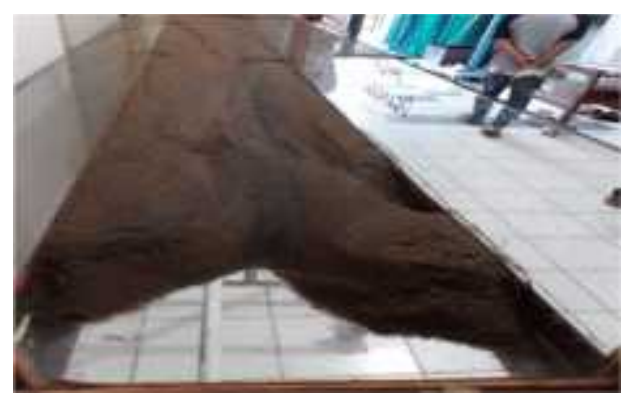

Gambar 5. Pola Erosi dan Sedimentasi pada waktu 90 Menit

Gambar 5 adalah pola yang terjadi selama interval waktu simulasi selama 60 menit dan terlihat pola pergerakan sedimen mulai meningkatkan erosi dan akumulasi sedimen di tengah tepi sungai dan sebelah kiri sungai tetapi masih erosi yang membesar di tengah bentuk tubuh sungai bergelombang pola ke tengah sungai.

Sedimen dasar yang terdapat pada muara sungai sekanak arahnya terlihat beragam,hal ini terjadi karena banyak factor yang mempengaruhi proses sebaran sedimen pada muara sungai,bahwa populasi endapan delta akan lebih komplek karena adanya berbagai arus,pasang surut,arus sungai,gelombang dan arahnya yang bolak balik.

Pola sebaran ukuran butiran dengan jenis pasir lanau menandakan bahwa terdapat hubungan antara arus dengan distribusi sebaran sedimen. Berdasarkan hasil simulasi model yang dilakukan diketahui bahwa kondisi pola sedimen yang diakibatkan kecepatan air yang lemah akan menyebabkan partikel sedimen dengan ukuran yang lebih besar akan lebih mudah terendapkan sedangkan partikel sedimen yang lebih kecil akan terdeposisi.

Hasil simulasi model menujukan pola sedimentasi yang terjadi banyak terdapat penumpukan sedimen pada bagian sebalah kiri dan mengikis pada bagian tengah hal ini menunjukan bahwa pengaruh kecepatan air sangat memperngaruhi pola sedimen.

\section{KESIMPULAN DAN SARAN}

\subsection{Kesimpulan}

1. Dari prediksi besarnya angkutan sedimen yang terjadi pada muara sungai sekanak sebesar adalah sebesar 105,926 $\mathrm{m}^{3} /$ hariatau6720 $\mathrm{m}^{3} /$ tahun dengan periodewaktu pengerukan adalah29 bulan atau 2 tahun sekali minimal dilakukandilakukan pengerukanbadansungai.

2. Pola sedimentasi yang terjadi di muara sungai sekanak berbentuk "chute and pool"

\subsection{Saran}

1. Perlu adanya penelitian lebih lanjut terhadap angkutan sedimen dasar, supaya data penelitian ini dapat dijadikan referensi untuk mengetahui perubahan angkutan sedimen.

2. Pada penelitian selanjutnya untuk pengukuran sedimen secara langsung dilapangan lebih menyeluruh sehingga didapatkan data yang dapat mewakili seluruh penampang yang ditinjau.

\section{Ucapan Terima Kasih}

Ucapan terima kasih disampaikan kepada bapak Ir. Suparji S ST, MT Kepala BBWSSVIII yang telah banyak memberikan bantuan berupa data yang sangat penting untuk melakukan simulasi hidrolik di laboratorium.

\section{Daftar Pustaka}

A Syarifudin, The $2^{\text {nd }}$ International Conference on Informatics, Environment, Energy and Applications (IEEA 2013), Bali, Indonesia, March 16-17, 2013, JOCET (Journal of Clean Energy and Technology) Journal ISSN: 1793-821X Vol. 2, No. 1, January 2014. (2013)

A Syarifudin, 5th ICIBA International conference on information technology \& Engineering Application, Palembang, Indonesia, 2015

A Syarifudin, The influence of Musi River Sedimentation to TheAquatic Environmenthttps://doi.org/10.1051/matec conf/201710104026 Volume 101 (2017) 
MATEC Web Conf, 101(2017)04026 [published online 09 March 2017]

Cahyono Ikhsan, (2007), Pengaruh Variasi debit air terhadap laju bed load pada saluran terbuka dengan pola aliran steady flow, Media Teknik Sipil, Januari 2017

Chalov S., Ermakova G. Fluvial response to climate change: a case study ofnorthern Russian rivers // Cold Region Hydrology in a Changing Climate. IAHSPubl. 346, 2011. P. 111-119

C Leo Van Rijn, (1990), Principles of Fluid Flow and Surface Waves in River, Estuaries, Seas and Ocean, Aqua Publications Nederlands

Ferdian Agung Nugroho, (2010), The control of Sedimentation in Irrigation Channel Using Floating Objects Placement, thesis of Civil Engineering of SebelasMaret University, Surakarta

Jessica Pineda Z. (2005), Maintenance of river ecosystems within urban areas", thesis, International Institute for Geoinformation Science and Earth ObservaionEnschede, Urban Planning and Land A dministration, Netherlands

Marfai, Muh. Aris, (2003), GIS Modeling of River and Tidal Flood Hazards in a Waterfront City, M. Sc Thesis, ITC Enschede, The Netherlands

Reini Silvia. I. (2006), Study Of Sediment Transport At Musi River In Front Of Fort KutoBesak Palembang, Proceedings HEDS-SST, HEDS Forum, Jakarta

Robert. J. Kodoatie, Sugiyanto, (2002), "Flood causes and methods of control in an environmental perspective.", Yogyakarta

Syarifudin A, (2017), Applied Hydrology (Andi Publishing Company) pp 4548Syarifudin A, (2017), Environmentally Urban Drainage (Andi Publishing Company) pp 38-42

Suripin, (2004), Sustainable of Urban Drainage System (Andi Publishing Company) pp 176-179

Shu AP, Tang C, Zhang X, et al. (2015), Deposition morphology of non- homogeneous debris flow and its energy characteristics.Journal of Mountain Science, 12(5). DOI:10.1007/s11629-0143188-9

Sosrodarsono Suyono, Kensaku Takeda, (2003). Hydrology for Watering, PradnyaParamita, Jakarta.

Triatmodjo, Bambang. (1993). Hydraulics I. Beta Offset.Yogyakarta.

Triatmodjo, Bambang. (1993). Hydraulics II. Offset Beta. Yogyakarta

Wanshun Zhang, YanhongXu, Yanru Wang, and Hong Peng (2014), Modeling Sediment Transport and River Bed Evolution in River System" Journal of Clean Energy Technologies, Vol. 2, No. 2, April 2014 